\title{
Nursing Students' Opinions on Facilitating and Hindering Factors in the Clinical Training Setting
}

\author{
Iman Abdullah Mohammed Abdulmutalib ${ }^{1, ~ *, ~ N a g l a a ~ A b d e l a z i z ~ M a h m o u d ~ E l ~ S e e s y ~}{ }^{2}$, \\ Shadia Abdallah Hassan Yousuf ${ }^{3}$ \\ ${ }^{1}$ Department of Medical-Surgical Nursing, Faculty of Nursing, Ain Shams University, Cairo, Egypt \\ ${ }^{2}$ Department of Nursing Administration, Faculty of Nursing, Alexandria University, Alexandria, Egypt \\ ${ }^{3}$ Department of Community Nursing, Faculty of Nursing, King Abdulaziz University, Jeddah, KSA
}

\author{
Email address: \\ immotaleb@yahoo.ca (I. A. M. Abdulmutalib) \\ ${ }^{*}$ Corresponding author
}

\section{To cite this article:}

Iman Abdullah Mohammed Abdulmutalib, Naglaa Abdelaziz Mahmoud El Seesy, Shadia Abdallah Hassan Yousuf. Nursing Students' Opinions on Facilitating and Hindering Factors in the Clinical Training Setting. American Journal of Nursing Science .

Vol. 8, No. 1, 2019, pp. 1-8. doi: 10.11648/j.ajns.20190801.11

Received: December 3, 2018; Accepted: December 13, 2018; Published: January 19, 2019

\begin{abstract}
Clinical training for nursing students is essential in any nursing program because nursing is a discipline that requires students to apply theoretical knowledge into clinical training setting and acquire various skills to enhance their performance. The study aimed to identify nursing students' opinions on facilitating and hindering factors in the clinical training setting. A descriptive cross-sectional design was used. The study was conducted in the Faculty of Nursing King Abdulaziz University on 86 student nurses enrolled in $2^{\text {nd }}, 3^{\text {rd }}$, and $4^{\text {th }}$ year. The tool was developed by the researchers and consists of two parts: Part I: Demographic characteristics. Part II: This part includes 42 items, 15 items related to facilitating factors and 27 items hindering factors. The study results showed that there was a statistically significant difference among all three academic years of the student nurses regarding common hindering factors named patient's morning care, difficulty in being initiative or not being self-reliant, feeling of not being treated seriously/receiving condescending comments from the supervisor, and insufficient supervision or supervisors irritated or not interested. While no statistically significant difference among all three academic years of the student nurses opinions in relation to the common facilitating factors. Conclusions: The common facilitating factors among all students in the present study were patient family cooperation help me to be more confident, having opportunities to practice different tasks gives confidence, more practice makes learning from mistakes, being receiving feedback gives self-confidence, having a good collaboration with staff gives the confidence to ask questions or show weakness, and working with another student-helped make the work and care of the client go smoothly. Furthermore, the common hindering factors among all students were fear of making mistakes, evaluation by faculty, patient's morning care, lack of time to accomplish the required tasks, difficulty in being initiative or not being self-reliant, receiving condescending comments from the supervisor, and insufficient supervision and supervisors not interested. Recommendations: Develop an organized supervision system, through specialized clinical supervisors, and assigned preceptors from the hospital to help the students in the clinical training. Develop a standardized evaluation form to support and fair evaluation. Prepare the students before direct contact with the patients, through attending simulation training to minimize mistakes when contact with the patients in the clinical setting.
\end{abstract}

Keywords: Clinical-Nursing Practice, Facilitating, Hindering Factors, Nursing Students

\section{Introduction}

\subsection{Background}

Clinical learning training for nursing students is essential in any nursing program because nursing is a discipline that requires students to acquire various skills [1]. The nursing educators should delve into the factors identified with a goal to decide which strategies can improve learning and 
transferring of theory to practice in the clinical areas [2]. Fifty percent of nursing education at King Abdulaziz University is clinical training.

Clinical learning training is a crucial feature of nursing teaching. This is because it is the application of theoretical information into clinical training as well as being the foundation of nursing as a health profession [3]. To achieve efficient clinical learning training, the clinical setting needs to be supportive, including the climate of the clinical setting, and association shared between the clinical staff supervisors and mentors [4].

The effective mutual association between clinical staff and nursing students is necessary in order to form a positive learning environment. The clinical staff should be prepared in their role of helping in the socialization of nursing students in the clinical setting, as they are teaching students to care [2].

The clinical learning environment is important to achieve the defined learning outcomes of the program [5]. The clinical environment includes the clinical settings, nursing staff, patients; nurse tutors etc. [6]. The quality of the clinical learning environment may influence the achievement of the learning outcomes. Therefore, a plan is required to select a best clinical learning environment, which is difficult. In addition, having a positive clinical environment may affect the career choices of student nurses [7, 8].

Nursing students perceive the clinical environment as a source of anxiety, stress, fear and vulnerable place. The relationship between the clinical instructors, staff nurses and patients are very essential to build students' clinical training, adaptation and reduce the real shock $[9,10]$. The quality of clinical teaching is crucial to ensure achieving the learning outcomes [11]. Nursing students are required to develop various skills throughout clinical practice such as independence, critical thinking, communication, time management, sense of responsibility and clinical judgment. In addition, to implement ethics and safe practice [10]. The assurance of the clinical area optimal for learning is the job of nurse-educators [12]. The teaching and learning process in the clinical setting is expedited through practice that is culturally sensitive contextual and evidence-based $[13,14]$.

There have been numerous studies which assessed either facilitating or/and hindering factors of student learning in clinical practice. Chances to practice different tasks and have feedbacks from clinical tutors are considered facilitating factors. Communication with clinical mentors is important to enhance the learning process as perceived by nursing students. Examples of hindering factors that the students faced were the nurses, as they did not usually give the expected reply to their questions, and consequently would influence the opportunities for practice. In addition, the stressors for the first time clinical training include fear of making errors, criticisms from colleagues, unable to communicate with healthcare professionals and patients, give care to critically ill or terminal patients, lacking necessary skills and high expectation of the staff nurse towards nursing students [15-19].

It is hoped from this study to be vital for nursing educators in determining the factors that facilitate and hinder the nursing students in the clinical training setting and consequently, expedite the use of effective strategies to promote quality for clinical education in the future.

\subsection{The Aim of the Study}

Identify nursing students' opinions on facilitating and hindering factors in the clinical training setting at the Faculty of Nursing in King Abdulaziz University.

\section{Subjects and Methods}

\subsection{Research Design}

A descriptive cross-sectional research design was used.

\subsection{Setting}

The study was conducted at the Faculty of Nursing, King Abdulaziz University.

\subsection{Subjects}

The sample size was 86 nursing students enrolled in $2^{\text {nd }}$ $(20), 3^{\text {rd }}(34)$ and $4^{\text {th }}(32)$ academic year. They were selected at the end of the second semester by randomization to represent all the students. The inclusion criterion was students who attended one semester or more of clinical training.

\subsection{A tool of the Study}

The tool was developed by the researchers as guided by the literature (Dale, et al 2013; Elcigil and Sari, 2011, Jan 2010, Löfmark \& Wikblad, 2001, Sprengle, 2004, and Kleehammer et al 1990) [15-17] [19-21] and consisted of two parts.

\subsubsection{Part I}

Demographic characteristics data such as age, academic year and previous training experience in a clinical setting.

\subsubsection{Part II}

This part includes 42 items related to factors that affect learning in clinical practice. Those factors were classified to facilitating factors (15 items) and hindering factors (27 items). A five-point Likert scale was used to measure students' opinions by ranging from a Strongly Agree (5), to Strongly Disagree (1).

\subsection{Data Collection Procedure}

The ethical permission was obtained from the Faculty of Nursing, University of King Abdulaziz. The tool was reviewed and validated by a jury of seven experts from the medical-surgical nursing academic staff, faculty of nursing, King Abdulaziz University. This jury was chosen to evaluate/approve the clarity, feasibility, and relevance of tools and correspondingly, the needed corrections were done. The instrument recorded a Cronbach alpha score of 0.87 , a 
high level of internal consistency. Written consent was obtained from the participating students. The participation was voluntary. Furthermore, the students have ensured the privacy and confidentiality of their responses. The study was piloted on $10 \%$ of the participants who were selected randomly and later excluded from the actual study sample. Based on the results of the pilot sample, the necessary modification was done. The questionnaire was delivered manually to the participants to be completed and sent back. The data collection process is during the period of March April 2017. Data were collected, tabulated and analyzed statistically utilizing the statistical software SPSS version 20.

\section{Results}

\section{Demographic Data of the Studied Participants}

The demographic data of the studied participants showed that their age ranges between $19-23$ years old and all of them are female with Saudi nationality. The participants are classified into 20 students in the second year, 34 students in the third year, and 32 students in the fourth year. Regarding the training experience in a clinical setting, it was found that the second-year students had experiences in the medical, surgical units and dressing clinic. Whereas, the third year students had experiences in the medical, surgical, dressing clinic, endoscopy unit, day-care, cardiac catheterization, operating room, paediatrics, and obstetrics \& gynaecological units. Finally, the fourth year students had experiences in the medical, surgical, intensive care, coronary care, dialysis, emergency department, paediatric intensive care, and obstetrics \& gynaecological units.

Table 1 illustrates the mean score distribution of the nursing students opinions (second, third, and fourth academic year) toward facilitating factors in the clinical setting. It was found that the second academic year students show the higher mean score (4.75) in their response to more practice makes learning from mistakes. In addition, the third academic year nursing students' opinions towards the facilitating factors showed the higher mean score (4.74) with respect to having opportunities to practice different tasks gives confidence. Furthermore, the fourth academic year nursing students' opinions towards the facilitating factors showed that the higher mean score (4.63) was in their response to more practice makes learning from mistakes.

Table 2 shows the mean score distribution of the nursing students' opinions (second, third, and fourth academic year) toward hindering factors in the clinical setting. The higher mean score (4.20) related to lack of time to accomplish the required tasks is among second academic year nursing students. Whereas, the higher mean score (4.59) is among third academic year nursing students' opinions in their responses to insufficient supervision and supervisors not interested. Moreover, fourth-year students' opinions showed a higher mean score (4.0) toward the fear of making mistakes among the hindering factors.

Table 3 compares the student nurses' opinions of all three academic years with respect to the common facilitating factors in the clinical setting. All students nurses in the three academic years $\left(2^{\text {nd }}, 3^{\text {rd }}\right.$, and $\left.4^{\text {th }}\right)$ agreed that the common facilitating factors in the clinical setting were patient family cooperation help me to be more confident, having opportunities to practice different tasks gives confidence, more practice makes learning from mistakes, being receiving feedback gives self-confidence, having a good collaboration with staff gives the confidence to ask questions or show weakness, and working with another student-helped make the work and care of the client go smoothly. There was no statistically significant difference among all three academic years of the student nurses opinions regarding those factors, $(\mathrm{p}=0.188,0.103,0.724,0.788,0.570$, and 0.129$)$ respectively.

Table 4 compares the student nurses' opinion of all three academic years regarding the common hindering factors in clinical setting practice. There was a statistically significant difference in the factor named patient's morning care, $(\mathrm{p}<$ 0.001) among all three academic years of the student nurses. Whereas, no statistically significant difference in this factor between second year and third-year students $\left(\mathrm{p}_{1}=0.798\right)$. It also observed that the difference was significant among second and fourth-year students $\left(\mathrm{p}_{1}<0.001\right)$. On the contrary, there is a significant difference between third and fourth-year students $\left(\mathrm{p}_{2}<0.001\right)$ regarding the same factor.

With regard to the factor difficulty in being initiative or not being self-reliant, it was found that the statistical difference is significant among all three academic years of the student nurses $(\mathrm{p}=0.001)$. The difference was statistically significant among second, and third-year students $(\mathrm{p} 1=0.004)$ and the third and fourth-year students ( $\mathrm{p} 2=0.001)$. However, no statistically significant difference was found among second and fourth-year students $(\mathrm{p} 1=0.985)$. The third-year students stated that this factor is considered more hindering than other years.

Regarding the factor receiving condescending comments from the supervisor there was a significant difference $(p=0.001)$ among all three academic years of the student nurses. The difference was statistically significant among the second, and third-year students $\left(\mathrm{p}_{1}=0.031\right)$ and the third and fourth-year students $\left(\mathrm{p}_{2}=0.001\right)$. Although, both the second and fourth- year students did not differ significantly in the same factor $\left(\mathrm{p}_{1}=0.590\right)$. It is worth noting that students in the third year have a higher mean score than the one of the other groups.

Regarding the factor insufficient supervision and supervisors not interested, there is a significant difference among all three academic years of the student nurses $(p=0.001)$. As shown in this factor, a difference among second and third-year students $\left(\mathrm{p}_{1}=0.001\right)$ was observed, and among third and fourth-year students $\left(\mathrm{p}_{2}=0.001\right)$. While the insignificant difference was noted among second and fourthyear students $\left(\mathrm{p}_{1}=0.836\right)$. It is observed from the table 4 that third-year students have a higher mean score than second and fourth-year students do.

Finally, there was no statistically significant difference among all three groups regarding hindering factors, fear of making mistakes, evaluation by faculty, and lack of time to accomplish the required tasks, $(p=0.743,0.080$, and 0.106$)$ respectively. 
Table 1. The mean score distribution of the nursing students opinions (second, third, and fourth academic year) toward facilitating factors in the clinical setting $(n=86)$.

\begin{tabular}{|c|c|c|c|c|c|c|}
\hline \multirow{3}{*}{ Facilitating factors } & \multicolumn{6}{|c|}{ Nursing students opinions } \\
\hline & \multicolumn{2}{|c|}{$2^{\text {nd }}(n=20)$} & \multicolumn{2}{|c|}{$3^{\text {rd }}(n=34)$} & \multicolumn{2}{|c|}{$4^{\text {th }}(n=32)$} \\
\hline & Mean & Rank & Mean & Rank & Mean & Rank \\
\hline Cooperation from the registered nurse help me to be more confident & 3.95 & 11 & 4.18 & 10 & 4.25 & 6 \\
\hline Community understanding to the role of the nurse facilitate my work & 4.0 & 10 & 4.18 & 10 & 3.88 & 13 \\
\hline Patient family cooperation help me to be more confident & 4.45 & 3 & 4.35 & 7 & 4.09 & 10 \\
\hline Physicians appreciation for the nurses' role motivate the student learning & 3.65 & 14 & 4.09 & 13 & 3.88 & 13 \\
\hline To be allowed to take responsibility. & 3.80 & 12 & 4.12 & 12 & 4.09 & 10 \\
\hline Being allowed to work independently & 3.55 & 15 & 3.32 & 14 & 3.69 & 15 \\
\hline Having opportunities to practice different tasks gives confidence. & 4.45 & 3 & 4.74 & 1 & 4.44 & 2 \\
\hline More practice makes learning from mistakes & 4.75 & 1 & 4.68 & 2 & 4.63 & 1 \\
\hline Being receiving feedback gives self-confidence. & 4.50 & 2 & 4.41 & 5 & 4.34 & 3 \\
\hline Having a good collaboration with staff gives the confidence to ask questions or show weakness & 4.45 & 3 & 4.26 & 8 & 4.22 & 7 \\
\hline Getting an understanding of the whole situation & 4.05 & 9 & 4.56 & 4 & 4.13 & 8 \\
\hline Have control over the situation & 3.80 & 12 & 4.41 & 5 & 4.0 & 12 \\
\hline Working with another student-helped make, the work and care of the client go smoothly. & 4.25 & 8 & 4.65 & 3 & 4.13 & 8 \\
\hline Started to learn about the role of the nurse, responsibilities, delegation of work & 4.35 & 7 & 4.24 & 9 & 4.28 & 5 \\
\hline The procedures I have learned in the skills lab will be practicing in the clinical setting & 4.40 & 6 & 2.53 & 15 & 4.31 & 4 \\
\hline
\end{tabular}

Table 2. The mean score distribution of the nursing students opinions (second, third, and fourth academic year) toward hindering factors in the clinical setting $(n=86)$

\begin{tabular}{|c|c|c|c|c|c|c|}
\hline \multirow{3}{*}{ Hindering factors } & \multicolumn{6}{|c|}{ Nursing students opinions } \\
\hline & \multicolumn{2}{|c|}{$2^{\text {nd }}(n=20)$} & \multicolumn{2}{|c|}{$3^{\text {rd }}(n=34)$} & \multicolumn{2}{|c|}{$4^{\text {th }}(n=32)$} \\
\hline & Mean & Rank & Mean & Rank & Mean & Rank \\
\hline Fear of making mistakes. & 4.15 & 2 & 3.91 & 8 & 4.0 & 1 \\
\hline Fear of performing procedures (ie, injections). & 2.85 & 24 & 3.21 & 16 & 2.94 & 20 \\
\hline Fear to handle equipment (ie, intravenous pumps). & 2.50 & 26 & 2.41 & 24 & 2.31 & 27 \\
\hline Talking to physicians. & 2.35 & 27 & 3.18 & 19 & 2.78 & 22 \\
\hline Being observed by instructors. & 3.35 & 12 & 2.82 & 21 & 3.24 & 16 \\
\hline Patient teaching (communication \& knowledge). & 3.20 & 16 & 2.44 & 23 & 2.76 & 23 \\
\hline Initial clinical experience. & 3.70 & 5 & 3.53 & 13 & 3.53 & 12 \\
\hline Patient's morning care. & 3.90 & 3 & 3.68 & 10 & 3.13 & 17 \\
\hline Asking questions to faculty. & 3.50 & 8 & 2.0 & 25 & 2.62 & 24 \\
\hline Talking to the patient's family. & 3.10 & 19 & 2.0 & 26 & 2.36 & 26 \\
\hline Reporting to head nurse. & 3.10 & 19 & 3.29 & 15 & 2.98 & 19 \\
\hline Talking to the patient. & 3.10 & 19 & 1.97 & 27 & 2.41 & 25 \\
\hline Being late. & 2.75 & 25 & 2.68 & 22 & 2.86 & 21 \\
\hline The supervisor does not rely on the student. & 3.0 & 23 & 4.21 & 3 & 3.45 & 13 \\
\hline Receiving condescending comments from the supervisor. & 3.65 & 6 & 4.44 & 2 & 3.85 & 2 \\
\hline Insufficient supervision and supervisors not interested. & 3.25 & 14 & 4.59 & 1 & 3.84 & 3 \\
\hline Lack of feedback or opportunities to reflect & 3.15 & 17 & 4.06 & 6 & 3.70 & 6 \\
\hline Supervision lacks continuity. & 3.25 & 14 & 2.97 & 20 & 3.01 & 18 \\
\hline Lack of guidelines for nursing practice in the working climate & 3.50 & 8 & 3.59 & 12 & 3.43 & 14 \\
\hline The lack of time to accomplish the required tasks. & 4.20 & 1 & 3.47 & 14 & 3.79 & 5 \\
\hline The stress of a long time. & 3.35 & 12 & 4.12 & 4 & 3.69 & 7 \\
\hline Lack of opportunities to practice and not allowed taking part. & 3.60 & 7 & 4.0 & 7 & 3.83 & 4 \\
\hline Experiences of insufficiency or own failure & 3.15 & 17 & 3.91 & 9 & 3.59 & 9 \\
\hline Difficulties in taking initiatives action & 3.45 & 10 & 3.68 & 11 & 3.56 & 11 \\
\hline Insufficient knowledge. & 3.10 & 19 & 4.09 & 5 & 3.65 & 8 \\
\hline
\end{tabular}

Table 3. Comparison between second, third, and fourth-year students' opinions in regarding the common facilitating factors in the clinical setting ( $n=86)$.

\begin{tabular}{|c|c|c|c|c|c|}
\hline \multirow{2}{*}{ Common facilitating factors } & \multicolumn{3}{|c|}{ Nursing students opinions } & \multicolumn{2}{|c|}{ Test of significant } \\
\hline & $2^{\text {nd }}(n=20)$ & $3^{\text {rd }}(n=34)$ & $4^{\text {th }}(n=32)$ & $\mathbf{F}$ & $\mathbf{p}$ \\
\hline Patient family cooperation helps to be more confident. & $4.45 \pm 0.51$ & $4.35 \pm 0.65$ & $4.09 \pm 0.93$ & 1.707 & 0.188 \\
\hline Having opportunities to practice different tasks gives confidence. & $4.45 \pm 0.60$ & $4.74 \pm 0.67$ & $4.44 \pm 0.56$ & 2.331 & 0.103 \\
\hline More practice makes learning from mistakes & $0.44 \pm 0.10$ & $0.64 \pm 0.11$ & $0.49 \pm 0.09$ & 0.324 & 0.724 \\
\hline Being receiving feedback, gives self-confidence. & $4.50 \pm 0.95$ & $4.41 \pm 0.78$ & $4.34 \pm 0.70$ & 0.239 & 0.788 \\
\hline $\begin{array}{l}\text { Having a good collaboration with staff gives the confidence to ask questions or } \\
\text { show weakness }\end{array}$ & $4.45 \pm 0.51$ & $4.26 \pm 0.67$ & $4.22 \pm 1.01$ & 0.566 & 0.570 \\
\hline $\begin{array}{l}\text { Working with another student-helped make, the work and care of the client go } \\
\text { smoothly. }\end{array}$ & $4.25 \pm 1.21$ & $4.65 \pm 0.98$ & $4.13 \pm 1.07$ & 2.101 & 0.129 \\
\hline
\end{tabular}


Table 4. Comparison between second, third, and fourth-year students' opinions in regarding the common hindering factors in the clinical setting ( $n=86$ ).

\begin{tabular}{|c|c|c|c|c|c|}
\hline \multirow{2}{*}{ Common hindering factors } & \multicolumn{3}{|c|}{ Nursing students opinions } & \multicolumn{2}{|c|}{ Test of significant } \\
\hline & $2^{\text {nd }}(n=20)$ & $3^{\text {rd }}(n=34)$ & $4^{\text {th }}(n=32)$ & $\mathbf{F}$ & $\mathbf{p}$ \\
\hline Fear of making mistakes. & $4.15 \pm 0.88$ & $3.91 \pm 1.26$ & $4.0 \pm 1.02$ & 0.299 & 0.743 \\
\hline Evaluation by faculty. & $3.90 \pm 0.85$ & $3.21 \pm 1.41$ & $3.72 \pm 1.11$ & 2.600 & 0.080 \\
\hline Patient's morning care. & $3.90 \pm 1.02$ & $3.68 \pm 1.32$ & $2.06 \pm 1.11$ & $21.081^{*}$ & $<0.001$ \\
\hline $\mathrm{p}_{1}$ & & 0.798 & $<0.001^{*}$ & & \\
\hline $\mathrm{p}_{2}$ & & & $<0.001^{*}$ & & \\
\hline The lack of time to accomplish the required tasks. & $4.20 \pm 1.06$ & $3.47 \pm 1.44$ & $3.88 \pm 1.10$ & 2.305 & 0.106 \\
\hline Difficulty in being initiative or not being self-reliant. & $3.0 \pm 1.26$ & $4.21 \pm 1.27$ & $2.94 \pm 1.24$ & $10.066^{*}$ & $<0.001$ \\
\hline $\mathrm{p}_{1}$ & & $0.004^{*}$ & 0.985 & & \\
\hline $\mathrm{p}_{2}$ & & & $<0.001^{*}$ & & \\
\hline Receiving condescending comments from the supervisor. & $3.65 \pm 1.04$ & $4.44 \pm 0.89$ & $3.34 \pm 1.18$ & $9.614^{*}$ & $<0.001$ \\
\hline 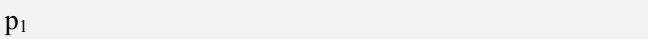 & & $0.031^{*}$ & 0.590 & & \\
\hline $\mathrm{p}_{2}$ & & & $<0.001^{*}$ & & \\
\hline Insufficient supervision and supervisors not interested. & $3.25 \pm 1.25$ & $4.59 \pm 0.89$ & $3.44 \pm 1.19$ & $12.956^{*}$ & $<0.001$ \\
\hline $\mathrm{p}_{1}$ & & $<0.001^{*}$ & 0.836 & & \\
\hline $\mathrm{p}_{2}$ & & & $<0.001^{*}$ & & \\
\hline
\end{tabular}

F: F test (ANOVA)

$\mathrm{p}_{1}$ : to compare between $2^{\text {nd }}$ year, and each both of $3^{\text {rd }}, 4^{\text {th }}$ year students

$\mathrm{p}_{2}$ : to compare between $3^{\text {rd }}, 4^{\text {th }}$ year students.

*: Statistically significant at $\mathrm{p} \leq 0.05$

\section{Discussion}

Clinical practice is important for undergraduate students. Clinical practice provides opportunities for nursing students to implement what is learned in theory [22].

The result of the students' opinions towards the clinical experience showed that one of the common hindering factors among the nursing students of all three academic years is the fear of making mistakes. This could be due to the cultural obligation to respect human dignity and the students' lack of clinical experience. This study's finding aligns with Johnson \& Young, (2011) [23] who reported that mistakes in clinical practice are a major and disturbing problem within nursing practice. This result is also in the same line with Sharif \& Masoumi, (2005) [24], Löfmark \& Wikblad, (2001) [19] who mentioned that students are mainly anxious about making errors when performing patient procedures or injuring patients because they have no experience and knowledge. These fears and anxieties adversely affect the competence of students to practice effectively $[25,26]$.

The participants of the present study stated that evaluation by faculty is one of the most common hindering factors. This result could be due to the shortage of staff in a particular specialty and consequently, staff members from another specialty/departments might attend as well. Therefore, the students feel that some clinical instructors are biased. Baraz et al (2015) [27] stated that the usage of non-standardized forms to evaluate students and lack of exposure to learning situation are considered major obstacles to learning.

The current study also found that patient's morning care and lack of time to accomplish the required tasks are rated as common hindering factors in clinical setting practice. This result is consistent with Rajeswaran, (2016) [26] who reported that the shortage of time provided for the procedures was irritating for the student nurses.

Furthermore, insufficient supervision and supervisors not interested, receiving condescending comments from the supervisor and difficulty in being initiative or not being self-reliant are considered as common hindering factors in clinical setting practice related to clinical supervision. This finding is due to the heavy workload and lack of specialization of clinical supervisors. This result is in agreement with Rajeswaran, (2016) [26] who reported the lack of faculties for clinical settings. Clinical supervision is an important component in supporting learning in the clinical setting [28]. According to Melincavage (2011), [29] the clinical instructor's presence in stressful occasions diminishes the students' fear and anxiety and increases their confidence.

Generally, there was a significant difference in the factor named as patient's morning care, among all nursing students of the three academic years. The difference was insignificant among 2nd year and 3rd-year students. However, the difference was significant among 2nd and 4th-year students and 3rd year and 4th-year students. The second year students have a higher mean score for that factor than other years. This could be due to the initial experience for second-year students whose mainly training focused on fundamentals nursing procedures such as patient's morning care.

Regarding the factor difficulty in taking initiative or not being self-reliant, it was found that there is a significant difference among all nursing students of the three academic years. The difference was significant among 2 nd and 3rdyear students and 3rd year and 4th-year students. Although, an insignificant difference was recognized among 2nd and 4th-year students. Third-year students have a higher mean score than fourth- year students. In addition, second-year students have a higher mean score in relation to this factor than fourth-year students. This could be because of the students' progress in clinical practice where they become more initiative and independent in performing clinical procedures alone.

Regarding the factor receiving condescending comments 
from the supervisor, there was a significant difference among all three academic years of the student nurses. The difference was significant between 2 nd, and $3^{\text {rd }}$-year students and 3 rdyear and 4th-year students. Whereas an insignificant difference was found among 2 nd and 4 th-year students. The 3rd-year students recorded a higher score than 2nd and 4thyear students. As clinical supervisors are responsible for clinical training that differs from their specialties, they cannot constantly give condescending comments or feedback for students.

Regarding the hindering factor insufficient supervision and supervisors not interested, there was a statistical difference among all three academic years of the student nurses. For this factor, it was found that the difference was significant among 2nd and 3rd-students. While it was insignificant among 2nd and 4th-year students. It is observed from the table 4 that third-year students have higher mean score than second and fourth-year students. This is because clinical supervisors who are from other specialties that differ from students training specialty are irritating or not interested so they cannot give the students sufficient supervision.

Most of nursing students of the three academic years highlighted one of the most common facilitating factors, which is having good collaboration with staff gives confidence. This finding is conforming to LekalakalaMokgele \& Caka, (2015) [30] study which stated that when students receive support from the staff, being self-directed and empowered, the clinical experience becomes easier.

The study revealed that the factor being receiving feedback gives self-confidence is one of the common facilitating factors in the clinical experiences. The nursing students highlighted that the involvement of supervisors, lecturers, and preceptors could improve their confidence in self, socialization and professional autonomy [31].

The study findings revealed that having opportunities to practice different tasks gives confidence is one of the common facilitating factors in clinical setting practice. This result could be due to that the practice of students under the supervision of staff nurses and clinical instructors without fear from falling in any mistake increase student self-confidence. A study by White, (2009) [32] confirmed that increasing the exposure of students to different situations helps in acquiring skills and improves self-confidence.

In the current study, being receiving feedback gives selfconfidence, and patient family cooperation helps me to be more confident are considered of the common facilitating factors in clinical setting practice. This study is congruent with Joolaee et al, (2016) [33] who reported that the students frequently mentioned that they felt confident when receiving appropriate support from their instructors and other sources of support in the ward. Also, Al sharani, (2015) [34] reported that one of the factors facilitating clinical placement is feedback from clinical lectures. Therefore, providing pleasant polite comment may help in students' growth and wonderful learning experiences even in difficult situations [15].

The study participants identified that having a good collaboration with staff gives the confidence to ask questions or show weakness is another common facilitating factor in their clinical practice. This finding is coherent with Cooper, et al, (2015) [35] who emphasized the significance of encouraging learning culture provided by nursing staff to help students to have constructive experience during their initial and consequent clinical experience

In addition, the participants state working with another student-helped make my work and care of the client go smoothly as another common facilitating factor in their clinical practice. In this respect, Chung et al; (2009) Wiener et al; (2009) and Vasan et al, (2009) [36-38] mentioned that learning which is based on team approach is useful to both course implementers and learners. It improves weak and strong students' performance academically.

Finally, participants in the study reported that more practice makes learning from mistakes. This is because the more time spent in a clinical setting, the more skills acquired by the students and the more they learn from their mistakes. According to Phuma-Ngaiyaye et al' study (2017), [39] the students stated that they are now competent in some skills because the preceptor is always helping the students during procedures, demonstrating, sometimes correcting when they make mistakes.

\section{Conclusions and Recommendations}

A study to identify nursing students' opinions on facilitating and hindering factors in the clinical training setting was conducted at the Faculty of Nursing in King Abdulaziz University. The opinions of 86 student nurses enrolled in 2nd, 3rd, and 4th year were assessed using a descriptive cross-sectional research design tool. The assessment tool was developed by the researchers and consists of two parts: Part I includes Demographic characteristics and Part II includes 42 items, of which, 15 items related to facilitating factors and 27 items hindering factors. Based on the results, the following conclusions and recommendations are presented.

\subsection{Conclusions}

The common facilitating factors among all students in the present study were patient family cooperation help me to be more confident, having opportunities to practice different tasks gives confidence, more practice makes learning from mistakes, being receiving feedback gives self-confidence, having a good collaboration with staff gives the confidence to ask questions or show weakness, working with another student-helped make, the work and care of the client go smoothly. Furthermore, the common hindering factors among all students were fear of making mistakes, evaluation by faculty, patient's morning care, lack of time to accomplish the required tasks, difficulty in being initiative or not being self-reliant, receiving condescending comments from the supervisor, and insufficient supervision and supervisors not interested. 


\subsection{Recommendations}

Based on the results of this study, it is recommended to:

1) Develop an organized supervision system, through specialized clinical supervisors, and assigned preceptors from the hospital to help the students in the clinical training.

2) Develop a standardized evaluation form to support and fairly evaluate the students by the clinical supervisors within the clinical setting since that is the common concern of students.

3) Prepare the students before direct contact with the patients by attending simulation training to minimize mistakes when being in contact with the patients in the clinical setting.

4) Re-shed light on the impending roles of the supervisors engaged in clinical learning so that sufficient training can be done to achieve the learning outcomes.

\section{Conflicts of Interest}

No authors have any possible conflict.

\section{References}

[1] Ali W. Caring and effective teaching behaviors of clinical nursing instructors in clinical area is perceived by their students. Journal of Education and practice. 2012; 3 (7): 15-26.

[2] Lawal J, Weaver S, Bryan V, Lindo J. Factors that influence the clinical learning experience of nursing students at a Caribbean school of nursing. Journal of Nursing Education and Practice. 2016; 6(4): 32-39.

[3] Killam LA, Heerschap C. Challenges to student learning in the clinical setting: A qualitative descriptive study. Nurse Education Today. 2013; 33(6): 684-691.

[4] Chaun OL, Barnett T. Student, tutor and staff nurse perceptions of the clinical learning environment. Nurse Education in Practice. 2012; 12(4): 192-197.

[5] Salminen L, Stolt M, Saarikoski M, Suikkala A, Vaartio H, Leino-Kilpi H. Future challenges for nursing education --a European perspective. Nurse Education Today. 2010; 30: 233238.

[6] Papp I, Markkanen M, von Bonsdorff M. Clinical environment as a learning environment: student nurses' perceptions concerning clinical learning experiences. Nurse Education Today. 2003; 23: 262-268.

[7] Fenush J, Hupcey J. An investigation of clinical unit choices graduating baccalaureate nursing Students. Journal of Professional Nursing. 2008; 24(2): 90-95.

[8] Marsland L, Hickey G. Planning a pathway in nursing: do course experiences influence job plans.? Nurse Education Today. 2003; 23: 226-235.

[9] Grealish L, Carroll G. Beyond perception and supervision: a third clinical teaching model emerges for Australian nursing education. Australian Journal of Advanced Nursing. 1998; 11: 26-33
[10] D'Souza a M, Karkada S, Parahoo K, Venkatesaperumal R. Perception of and satisfaction with the clinical learning environment among nursing students. Nurse Education Today. 2015; 35: 833-840.

[11] Löfmark A, Mårtensson G. Validation of the tool assessment of clinical education (AssCE): A study using Delphi method and clinical experts. Nurse Education Today. 2017; 50: 82-86.

[12] Levett-Jones T, Lathlean J, Higgins I, et al. Staff-student relationships and their impact on nursing students' belongingness and learning. Journal of Advanced Nursing. 2009; 65(2): 316- 324 .

[13] Carolan-Olah M, Kruger G. Final year students' learning experiences of the bachelor of midwifery course. Midwifery. 2013. http://dx.doi.org/10.1016/j.midw.2013.07.010.

[14] Tulbure C. Do different learning styles require differentiated teaching strategies? Procedia - Social and Behavioral Sciences. 2011; 11: 155- 159.

[15] Dale B, Leland A, and Gunnar Dale J. What Factors Facilitate Good Learning Experiences in Clinical Studies in Nursing: Bachelor Students' Perceptions. ISRN Nursing. 2013; Volume. Article ID 628679, 7 pages.

[16] Elçigil A, Sari H. Facilitating Factors in Clinical Education in Nursing. Nursing Clinical Education. 2011; 4 (2): 67-71.

[17] Jan W. Facilitating student learning in clinical practice. Nursing New Zealand. 2010; 16 (1): 14-6, 32.

[18] Nahas V, Yam M. Hong Kong nursing students' perceptions of effective clinical teachers. Journal of Nursing Education. 2001; 40(5): 233-7.

[19] Lö fmark A, Wikblad K. Facilitating and hindering factors for development of learning in clinical practice: a student perspective. Journal of Advanced Nursing. 2001; 34 (1): 4350 .

[20] Sprengel A. Reducing Student Anxiety by Using Clinical Peer Mentoring With Beginning Nursing Students. Nurse Educator. 2004; 29(6): 246-250.

[21] Kleehammer K, Hart L, Keck F. Nursing students' perceptions of anxiety-producing situations in the clinical setting. $J$ Nurs Educ. 1990; 29 (4): 183-187.

[22] Khan N, Alam B, Sabiha. Views of Nursing Students about Clinical Instructor behaviors That Affect the Development of Self-Confidence, Peshawar, KP, Pakistan. International Journal of Innovative Research \& Development. 2015; 4 (4): 10-20.

[23] Johnson M, Young H. The application of Aaronson's taxonomy to medication errors in nursing. Journal of Nursing Care Quality. 2011; 26(2): 128-135. doi: 10.1097/NCQ. 0b013e3181f54b14.

[24] Sharif F, Masoumi S. "A qualitative study of nursing student experiences of clinical practice. BMC Nursing. 2005; vol. 4, article $6,1-7$.

[25] Zieber M, Williams B. The Experience of Nursing Students Who Make Mistakes in Clinical Int. Jornal Nurse Education. 2015; Scholarsh; 12(1): 1-9.

[26] Rajeswaran L. Clinical Experiences of Nursing Students at a Selected Institute of Health Sciences in Botswana. Health Science Journal. 2016; 10(6): 471, ISSN 1791-809X. 
[27] Baraz S, Memarian R, Vanaki Z. Learning challenges of nursing students in clinical environments: A qualitative study in Iran. Journal Education Health Promot. 2015; 4: 52.

[28] Hickey M. Preceptor perceptions of new graduate nurse readiness for practice. J Nurses Staff Dev. 2007; 25: 35-41.

[29] Melincavage M. Student nurses' experiences of anxiety in the clinical setting. Nurse Education Today. 2011; 31(8): 785-9. doi: 10.1016/j. nedt.2011.05.007.

[30] Lekalakala-Mokgele E, Caka E. Facilitative and obstructive factors in the clinical learning environment: Experiences of pupil enrolled nurses. 2015; Original Research: 1-7.

[31] Hathorn D, Machtmes K, Tillman K. The lived experiences of nurses working with the student nurses in the clinical environment. Qual Rep. 2009; 14: 227-244.

[32] White A. Self-confidence: A concept analysis. Nursing Forum. 2009; 44(2): 103- 114. doi: 10.1111/j.17446198.2009.00133.x.

[33] Joolaee S, Farahani M, Amiri S, Varaei S. Support in Clinical Settings as Perceived by Nursing Students in Iran: A Qualitative Study. Nurse Midwifery Stud. 2016; March; 5(1): e31292.
[34] Al Shararani Y. Factors that assist undergraduates nursing students to cope with the experience of their first clinical placement [Master Thesis]. Adelaide University; 2015.

[35] Cooper J, Courty-pratt H, Fitzgerald M. Key influences identified by first-year undergraduates nursing students as impacting quality of clinical placement: A Qualitative study. Nurse Education today. 2015; 35(9): 10041008.

[36] Chung K, Rhee E, Baik H, Os A. The effect of team-based learning in medical ethics education. Med Teach. 2009; 31(11): 1013-1017.

[37] Wiener H, Plass R, Marz R. Team-based learning intensive course format for first-year medical students. Med Educ. 2009; 50(1): 69-76.

[38] Vasan N, DeFouw D, Compton S. A survey of student perceptions of team-based learning in anatomy curriculum: Favorable views unrelated to grades. Anat Sci Educ. 2009; 2(4): $150-155$.

[39] Phuma-Ngaiyaye E, Bvumbwe T, Chipeta C. Using preceptors to improve nursing students' clinical learning outcomes: A Malawian students' perspective. International Journal of Nursing Science. 2017; 4: $164-168$. 